\title{
Isolation and Molecular Characterization of Infectious Bronchitis Virus from Broiler Chickens, Egypt during 2014 -2016
}

\author{
Mohammed A. Lebdah ${ }^{1}$, Ahmed M. Hegazy ${ }^{1}$, Mohammed H. Hassan ${ }^{2}$ and Mai E. Mohammed ${ }^{2 *}$ \\ ${ }^{1}$ Avian and Rabbit Medicine Department, Faculty of Veterniary Medicine University, Zagazig, \\ 44511, Egypt \\ ${ }^{2}$ Poultry Diseases Department, Animal Health Research Institute, P.O. Box 264-Dokki, Giza, \\ 12618, Egypt
}

Article History: Received: 14/8/2016 Received in revised form: 13/12/2016 Accepted: 23/2/2017

\begin{abstract}
In this study, surveillance on infectious bronchitis virus strains in 75 Egyptian broiler chicken flocks was performed using real-time RT-PCR at eight Governorates during 2014-2016. The birds in the selected flocks were suffering from respiratory and renal manifestations. The results of the present study showed that $31(41 \%)$ samples were positive for IBV. All isolates were classified as variants using sequencing analysis of the obtained data and can be divided into 2 groups. Group I (variant) Egyptian IBV included isolates, EG-F728-1-2015-SP1, EG-F728-72015-SP1, EG-F862-3-2015-SP1, EG-F862-4-2015-SP1, EG-F888-2015-SP1, EG-F777-2015SP1 and EG-F183-1-2016-SP1 which were very close to IBV-IS-1494-06 and had amino acid sequence identities between $87.5 \%$ to $96.2 \%$. Group II (variant) Egyptian IBV included isolates, EG-F183-2-2016-SP1 and EG-F183-3-2016-SP1. These two IBV isolates were very close to IBV-IS/885 (variant 2) and they shared amino acid sequence identities from $92.3 \%$ to $97.1 \%$ with each other. In conclusion, different variants of IBV are present in broiler farms in high prevalence rate even in vaccinated flocks.
\end{abstract}

Keywords: IBV, Broiler, Egypt, Sequencing, Variants

\section{Introduction}

Infectious bronchitis (IB) is an acute, highly contagious disease of chickens of all ages causing high morbidity. Infectious Bronchitis Virus (IBV) is a member in order Nidovirales, family Coronaviridae, subfamily Coronavirinae, genus Gammacoronavirus and species Avian corona virus [1]. The virus not only targets the respiratory tract but also the urogenital tract and it can spread to different organs [2]. Vaccination is an essential tool to increase protection of chicken against newly emerged variant IBV strains that challenge the success of vaccination strategies [3]. Despite the routine IBV vaccination, outbreaks of IB frequently occur in the field due to the presence of different serotypes as well as the emergence of multiple subtypes, generated by point mutations, insertions, deletions, or RNA recombination of the $\mathrm{S} 1$ genes [4]. Therefore, continuous genotyping of IBV field strains is very important for screening the emergence of new variants as well as evaluating the existing vaccination programs. Recently, other novel genotypes were reported in Egypt and classified as Egyptian variant I (e.g. $\mathrm{CK} / \mathrm{Eg} / \mathrm{BSU}-3 / 2011)$ and Egyptian variant II (e.g. $\mathrm{CK} / \mathrm{Eg} / \mathrm{BSU}-2 / 2011$ ) [5]. In Egypt, commercial poultry industry suffered from heavy losses due to the emergence of new IBV strains that could compromise the immunity induced by most available vaccines [5]. The disease has been reported frequently in vaccinated and non-vaccinated flocks. The commonly used IBV attenuated vaccine is H120, while the Mass41 (M41) strain is commonly used in inactivated vaccines, but in many cases, renal damage was observed in IBvaccinated flocks. Thus, suggesting that the currently used IB vaccination procedures may not be providing adequate protection [6]. The aim of the current study was the isolation and molecular identification of IBV in diseased broiler flocks in different Egyptian Governorates. Sequencing of some identified

*Corresponding author email: (mahmoudsamir527@gmail.com), Poultry Diseases Department, Animal

Health Research Institute, P.O. Box 264-Dokki, Giza, 12618, Egypt. 
IBV and comparison with other obtained from GenBank were carried out.

\section{Material and Methods}

\section{Examined field samples}

The specimens included trachea, lung, kidney, cecal tonsil and air sac were collected from 75 broiler chicken flocks (5-10 birds per flock) with different age suffering from respiratory and renal troubles during 20142016 from 8 different Governorates in Egypt including Sharkia $(n=13)$, Qalubia $(n=15)$, Monofia $(n=7)$, Bani-Sueif $(n=5)$, Behara $(n=10)$, Giza $(n=8)$, Kafer elsheikh $(n=9)$ and Gharbia ( $\mathrm{n}=8)$ with age range 15 to 45 days.

Real time reverse transcription PCR (rRTPCR)

Viral RNA was extracted from the collected samples (trachea, kidney, air sac, cecal tonsil, lungs) using QIAamp Viral RNA Mini extraction kits (Qiagen Inc. Valencia CA) following the manufacturers' guidelines. One step rRT-PCR amplification of the coding regions of the SP1 gene was performed with gene-specific primer set using QuantiTect probe RT-PCR kits (Qiagen, Inc. Valencia CA). The sequences of the used primers are IBV5_GU391 Forward 5'-ACG TAT GAC TAC CCG CAG TAT TCA -'3, IBV5_GL533 Reverse 5'- AGA CCA GCC ACC ATG ATT GC-'3 target gene: N-gene [7]. IBV5-G probe 5'-FAM-CAC CAC CAG AAC CTG TCA CCT C-BHQ1-3'.

The reaction was performed in $25 \mu \mathrm{L}$ using QantiTect probe RT-PCR kits (Qiagen). each reaction contained $12.5 \mu \mathrm{L}$ of $2 \mathrm{x}$ QantiTect probe RT-PCR Master Mix, 0.1 units AmpErase (Qiagen), $5 \mu \mathrm{L}$ DNA template. Nuclease free water was added to a final volume of $25 \mu \mathrm{L}$, the reaction conditions were $50^{\circ} \mathrm{C}$ for $2 \mathrm{~min}, 95^{\circ} \mathrm{C}$ for $15 \mathrm{~min}$, followed by 40 cycles at $94^{\circ} \mathrm{C}$ for $15 \mathrm{sec}$ and $60^{\circ} \mathrm{C}$ for $60 \mathrm{sec}$ followed by plate read for fluorescence acquisition.

\section{Virus isolation}

Each IBV positive rRT-PCR sample (pooled samples) was inoculated into three, 9-11 dayold Specific Pathogen Free Embryonated Chicken Eggs (SPF-ECE) with $0.2 \mathrm{~mL}$ via allantoic cavity [8]. Inoculated eggs were incubated at $37{ }^{\circ} \mathrm{C}$ for $96 \mathrm{~h}$ and candled daily for embryo viability. All allantoic fluids from inoculated eggs were harvested and tested for hemagglutination using 1\% washed chicken red blood cells for the detection of presence of heamagglutination virus (s) in the collected samples [8].

\section{Conventional RT-PCR}

Reverse Transcriptase-Polymerase Chain Reaction (RT-PCR) for the amplification of hypervariable region of Spike 1 gene (HVR of Sp1 gene) sequence was carried out using Qiagen one step RT-PCR kit (Qiagen). The sequences of the used primers are IBV-S1-F Forward 5'-CAC TGG TAA TTT TTC AGA TGG- '3, IBV-S1-R Reverse 5'-C AGA TTG CTT ACA ACC ACC- '3 [9].

The final reaction volume was $25 \mu \mathrm{L}$ containing; $12.5 \mu \mathrm{L}$ RT-PCR Master mix, $5 \mu \mathrm{L}$ template RNA, forward primer $1 \mu \mathrm{L}$, reverse primer $1 \mu \mathrm{L}$, RNase free water was added to reach $25 \mu \mathrm{L}$ final volume. The reaction conditions were $95^{\circ} \mathrm{C}$ for $15 \mathrm{~min}$, followed by 40 cycles at $95^{\circ} \mathrm{C}$ for $30 \mathrm{sec}$ and $54^{\circ} \mathrm{C}$ for $45 \mathrm{sec}, 72^{\circ} \mathrm{C}$ for $2 \mathrm{~min}$ and final extension at $72^{\circ} \mathrm{C}$ for $10 \mathrm{~min}$. PCR products were visualized by electrophoresis in $1.5 \%$ agarose in $1 \mathrm{X}$ TAE, ethidium bromide was added to a concentration of $0.5 \mu \mathrm{g} / \mathrm{mL}$ for nucleic acid visualization.

\section{Sequencing and phylogenetic analysis}

Amplicons of proper size were purified using QIAquick Gel Extraction Kit (Qiagen Inc. Valencia CA) according to manufactures' instructions. Sequencing was carried out in Applied Biosystems 3130 automated DNA Sequencer (ABI, 3130, USA) using a ready reaction Bigdye Terminator V3.1 cycle sequencing kit (Perkin-Elmer/Applied Biosystems, Foster City, CA). BLAST® analysis (Basic Local Alignment Search Tool) [10] was initially performed to establish sequence identity with other sequences on the GenBank.

Pairwise sequence alignment of the aligned sequences for the SP1 gene was performed with the MegAlign module of Lasergene DNAStar software (Madison, WI) (Lasergene version 7.5, DNASTAR, Madison, WI, USA) to determine nucleotide an amino acid sequence identities and divergences. A phylogenetic tree of the amino acid sequences 
was constructed using MEGA6 software [11]. IBV sequences used for the alignments were obtained from the GenBank and EMBL database using multi sequence alignment (Table 1).

The tree topology was evaluated by 1000 boot strap analysis. The deduced amino acid sequences were determined to identify the pathotype of the isolated IBV strains. The Maximum Composite Likelihood method was used to compute the evolutionary distances (the units of the number of base substitutions per site). Evolutionary analyses were conducted in MEGA6.

Table 1: Reference and vaccinal IBV strains with GenBank accession numbers used in this study

\begin{tabular}{|c|c|c|}
\hline IBV strain & Tropism & $\begin{array}{l}\text { GenBank accession } \\
\text { number }\end{array}$ \\
\hline UK /4/91 & Vaccine & AF093794 \\
\hline Connecticut 46 & Respiratory & L18990 \\
\hline H120 & Vaccine & M21970 \\
\hline Ma5 & Vaccine & AY561713 \\
\hline M41 & Respiratory & AY561711 \\
\hline $\begin{array}{l}\text { IBV-CK-CH-Guangdong-Lezhu2- } \\
\text { 0905-S1 }\end{array}$ & Respiratory & GU938398 \\
\hline IBV-strain-NGA-310-2006 & Respiratory & FN182278 \\
\hline IBV-IS-1494-06-S1 & Proventriculus/Nephropathogenic & EU780077 \\
\hline IBV-isolate-IS-885-S1 & Nephropathogenic & AY279533 \\
\hline CR88121 & Vaccine & JN542567 \\
\hline $\mathbf{J} 2$ & Proventriculus & AF286303 \\
\hline Variant 2 & Respiratory/Nephropathogenic & AF093796 \\
\hline QXIBV & Proventriculus & AF193423 \\
\hline Ck/Eg/BSU-1/2011 & Nephropathogenic & JX174184 \\
\hline Ck/Eg/BSU-3/2011 & Nephropathogenic & JX174186 \\
\hline $\mathrm{Ck} / \mathrm{Eg} / \mathrm{BSU}-2 / 2011$ & Nephropathogenic & JX174185 \\
\hline Egypt/F/03 & Respiratory & DQ487085 \\
\hline D274 & Proventriculus/Nephropathogenic & X15832 \\
\hline $\mathbf{J X}$ & Respiratory & HQ018891 \\
\hline IBV/ck/CH/LNM/091017 & Respiratory & HM194682 \\
\hline IBV-strain-JF24-S1 & Respiratory & AF218851 \\
\hline D41 & Respiratory & AF036937 \\
\hline Variant 1 & Respiratory/Nephropathogenic & AF093795 \\
\hline Sul/01/09 & Respiratory/Nephropathogenic & GQ281656 \\
\hline EG/101 & Proventriculus/Nephropathogenic & HM851180 \\
\hline $\mathrm{Ck} / \mathrm{Eg} / \mathrm{BSU}-4 / 2011$ & Nephropathogenic & JX174187 \\
\hline
\end{tabular}

\section{Results}

\section{Clinical and postmortem findings}

The examined birds in the 75 broiler flocks showed clinical signs of depression, decrease in feed consumption and huddling together under heat source. Most of the birds were suffering from variable respiratory troubles in the form of gasping, lacrimation, nasal discharge and head swelling. Some of the examined chicks showed also renal signs in the form of chalky droppings, increased water intake and unsteady gait.

Postmortem examination of both freshly dead and sacrificed affected chickens revealed gross lesions in the form of serous, catarrhal, or caseous exudate in the trachea. Also, caseated plugs at tracheal bifurcation were observed in some examined flocks. In addition, of pneumonia, cloudiness of air sacs with or without yellow caseous exudates were observed. The kidneys of some birds were swollen and pale with tubules and ureters distended with ureats.

\section{Virus identification using rRT-PCR}

The results showed that out of 75 broiler farms $31(41 \%)$ pooled samples were positive for IBV. The highest prevalence rate of IBV virus was recorded in Bani-Sueif Governorate $(80 \%)$, while the lowest was recorded in Giza Governorate $12.5 \%$. 
Table 2: Result of RRT-PCR from different governorates:

\begin{tabular}{lccc}
\hline Locality & $\begin{array}{c}\text { Total number } \\
\text { examined }\end{array}$ & Positive number & $\%$ \\
\hline Sharkia & 13 & 7 & $54 \%$ \\
Monofia & 7 & 5 & $71 \%$ \\
Qalubia & 15 & 2 & $13 \%$ \\
Bani-Sueif & 5 & 4 & $80 \%$ \\
Behara & 10 & 2 & $20 \%$ \\
Giza & 8 & 1 & $12.5 \%$ \\
Kafer-Elshikh & 9 & 4 & $44 \%$ \\
Gharbia & 8 & 6 & $75 \%$ \\
Total & 75 & 31 & $41 \%$ \\
\hline
\end{tabular}

\section{Isolation in ECE}

Positive rRT-PCR samples were prepared to be inoculated in SPF Embryonated chicken eggs via allantoic route for virus isolation. Three passages of each isolate were performed and infected embryos showed dwarfism, curling, subcutaneous congestion and hemorrhage after the third passage. Examination of the allantoic fluid revealed negative HA test.
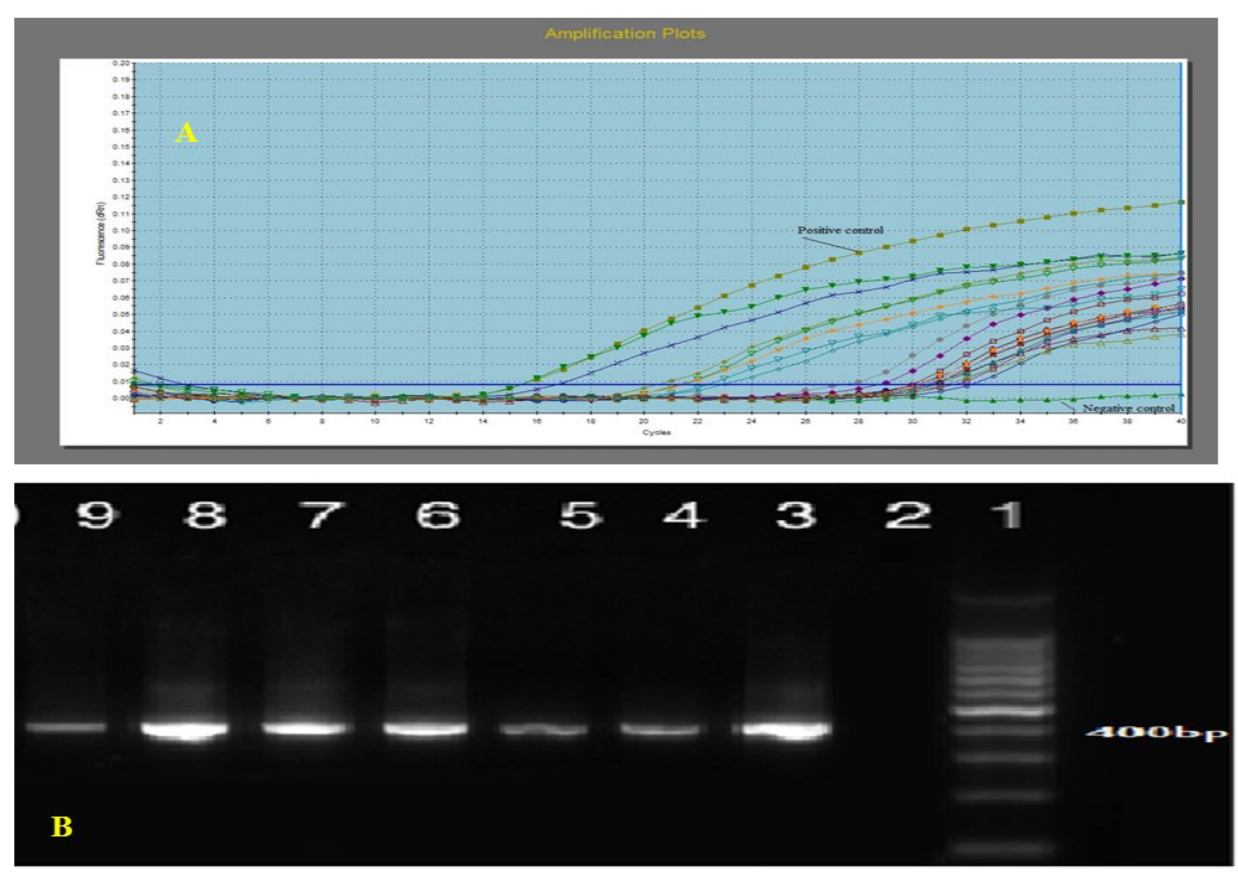

Figure 1: (A) Amplification curve for IBV samples using rRT-PCR. (B): Conventional PCR results for 6 isolates for IBV gene (Lane 1: 100 bp ladder, Lane 2: negative control, Lane 3: positive control obtained from poultry production reference lab., Dokki, Giza and Lanes 4-9: positive samples.

\section{Sequencing and phylogenetic analysis}

Nine samples were chosen based on the high CT values and lesion in embryos for SP1 gene characterization by sequencing. The analysis for the sequence data obtained from the nucleotide and amino acids sequences of HVR 3 of S1 gene was done to determine the differences among the 9 isolates. Table (1) shows the similarity percent for HVR 3 of S1 protein of IBV strains in comparison with other reference and vaccinal strains previously published in the GenBank database. Sequence analysis revealed that all the isolates were variants and divided into 2 groups. Group I (variant) Egyptian IBV included isolates, EGF728-1-2015-SP1, EG-F728-7-2015-SP1, EG- 
F862-3-2015-SP1, EG-F862-4-2015-SP1, EGF888-2015-SP1, EG-F777-2015-SP1 and EGF183-1-2016-SP1 which were very close to IBV-IS-1494-06 and had amino acid sequence identities between $87.5 \%$ to $96.2 \%$. Group II (variant) Egyptian IBV included isolates, EGF183-2-2016-SP1 and EG-F183-3-2016-SP1. These two IBV isolates were very close to IBV-IS/885 (variant 2) and they share amino acid sequence identities from $92.3 \%$ to $97.1 \%$ with each other (Figure 2).

In relation to vaccinal strains, the strains isolated in this study shared different amino acids identity. For the variant strains included in group I IBV-IS-1494-06 (Variant 2) including strain number EG-F728-1-2015-SP1 , EG-F728-7-2015-SP1 , EG-F862-3-2015SP1, EG-F862-4-2015-SP1 , EG-F888-2015SP1 , EG-F777-2015-SP1 and EG-F183-12016-SP1,They shared $76.6 \%$ to $88.5 \%$ with $\mathrm{H} 120$ and Ma5 and with $76 \%$ and $88.5 \%$ 4/91 and CR88, and, $80 \%$ with D274, respectively (Figures 2, 3).The other subgroup of the variant strains resembling IBV-isolate-IS885 , They shared amino acid similarity of $79 \%-83.7 \%, 79 \%-83.7 \%, 82.7-85.6 \%$, 77.982.7 and 81.7-84.6\% with H120, Ma5, 4/91, CR88 and D274, respectively (Figures 2, 3).

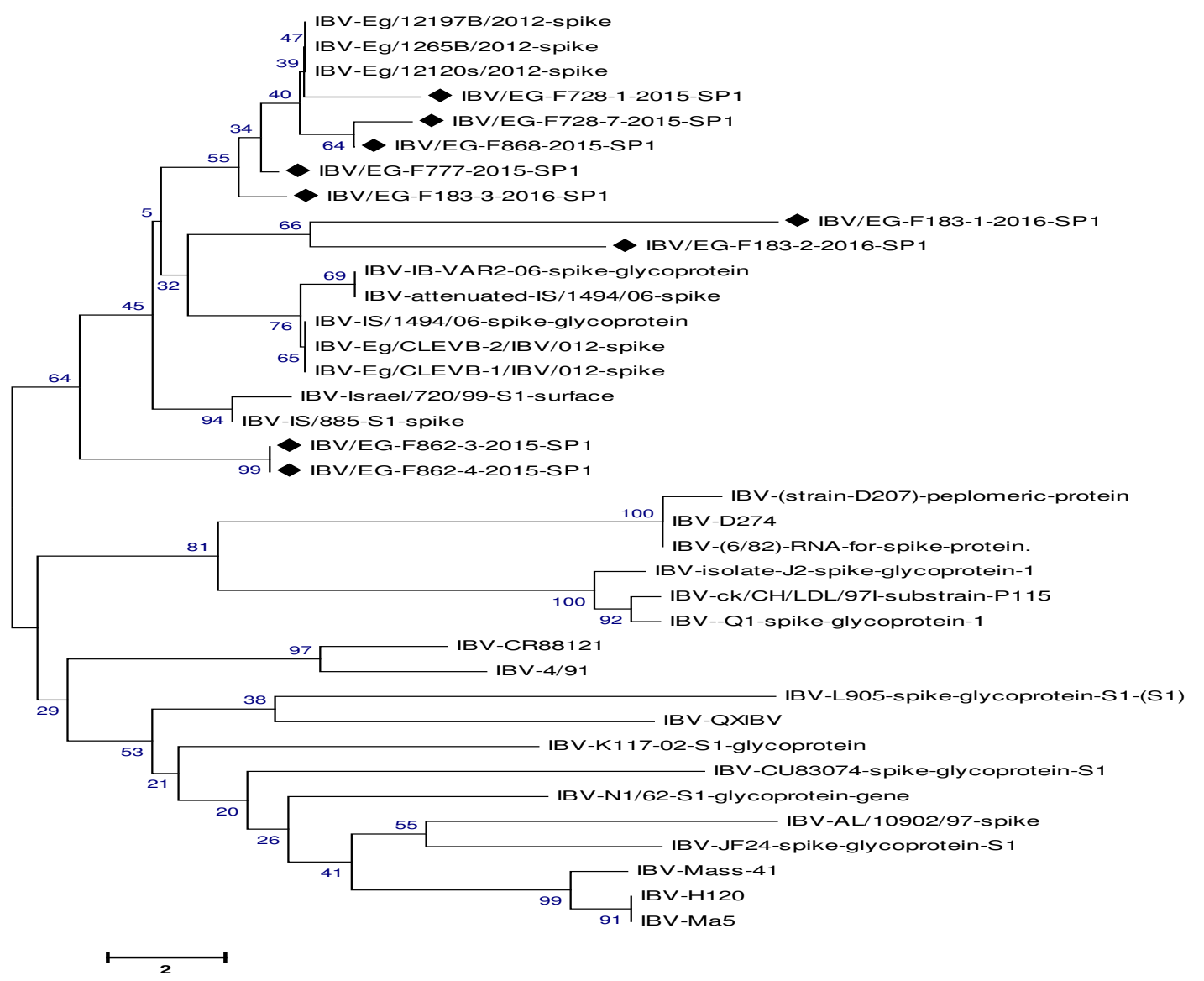

Figure 2: Phylogenetic tree of the partial S1 amino acids sequence of the nine Egyptian IBV isolates in this study, vaccinal strains present in Egypt and other reference IBV strains. The phylogenetic tree analysis was conducted by neighbor-joining method using bootstrap analysis (1000 replications) using Mega 6 software.

\section{Discussion}

Increased incidence of respiratory and nephritis symptoms related to infection with (IBV) in vaccinated and non-vaccinated Egyptian flocks have been reported and resulted in severe economic losses [12]. Different serotypes have been reported worldwide and new variant serotypes continue to be recognized [5,13]. Concerning the prevalence of IB in Egyptian chicken broiler farms, examination of 75 chicken flocks 
distributed in 8 Governorates from 2014 to 2016, revealed that $31(41 \%)$ were positive for IBV. Thus, indicating that IBV is widely prevalent in Egypt, since the initial description and isolation of the virus [14-16].

Infection of vaccinated flocks could be attributed to virus mutation, while, in nonvaccinated flocks is due to highly contagious nature of the virus and emergence of new IBV variants with nephropathogenic property $[4,5,17,18]$.

The observed clinical signs and gross lesions resembled those reported by several studies including wet eyes, swollen sinuses, reduced feed consumption and body weight, varying mortality, wet droppings, respiratory lesions and renal lesions [19-22].

Percentidentity

\begin{tabular}{|c|c|c|c|c|c|c|c|c|c|c|c|c|c|c|c|c|c|c|c|c|c|}
\hline & 1 & 2 & 3 & 4 & 5 & 6 & 7 & 8 & 9 & 10 & 11 & 12 & 13 & 14 & 15 & 16 & 17 & 18 & 19 & & \\
\hline 1 & & 95.2 & 95.2 & 96.2 & 84.68 & 84.6 & 84.6 & 87.5 & 83.7 & 86.5 & 98.1 & 98.1 & 93.3 & 93.3 & 99.0 & 99.0 & 88.5 & 89.49 & 98.1 & 1 & |BV-Eg/12120s/2012-spike \\
\hline 2 & 5.0 & & 100.0 & 96.2 & 84.68 & 84.6 & 84.6 & 88.5 & 84.6 & 87.5 & 93.3 & 95.2 & 92.3 & 92.3 & 96.2 & 94.2 & 87.5 & 90.49 & 95.2 & 2 & IBV-IS/1494/06-spike \\
\hline 3 & 5.0 & 0.0 & & 96.2 & 84.68 & 84.6 & 84.6 & 88.5 & 84.6 & 87.5 & 93.3 & 95.2 & 92.3 & 92.3 & 96.2 & 94.2 & 87.5 & 90.49 & 95.2 & 3 & |BV-Eg/CLEVB-2||BVV1012 \\
\hline 4 & 4.0 & 4.0 & 4.0 & & 82.78 & 82.7 & 82.7 & 86.5 & 84.6 & 85.6 & 94.2 & 94.2 & 95.2 & 95.2 & 95.2 & 97.1 & 87.5 & 92.39 & 97.1 & 4 & IBV-IS1885-S1-spike \\
\hline 5 & 17.3 & 17.3 & 17.3 & 19.7 & & 98.1 & 98.1 & 81.7 & 80.8 & 80.8 & 84.6 & 85.6 & 80.8 & 80.8 & 85.6 & 83.7 & 76.9 & 79.88 & 83.7 & 5 & IBV-Mass-41 \\
\hline 6 & 17.3 & 17.3 & 17.3 & 19.7 & 1.9 & & 100.0 & 80.8 & 79.8 & 80.8 & 84.6 & 85.6 & 80.8 & 80.8 & 85.6 & 83.7 & 76.9 & 79.88 & 83.7 & 6 & IBV-H12O \\
\hline 7 & 17.3 & 17.3 & 17.3 & 19.7 & 1.9 & 0.0 & & 80.8 & 79.8 & 80.8 & 84.6 & 85.6 & 80.8 & 80.8 & 85.6 & 83.7 & 76.9 & 79.88 & 83.7 & 7 & IBV-Na5 \\
\hline 8 & 13.7 & 12.6 & 12.6 & 14.9 & 21.02 & 22.3 & 22.3 & & 85.6 & 95.2 & 87.5 & 88.5 & 86.5 & 86.5 & 88.5 & 86.5 & 76.9 & 82.78 & 85.6 & 8 & IBV-CR88121 \\
\hline 9 & 18.5 & 17.3 & 17.3 & 17.3 & 22.32 & 23.6 & 23.6 & 16.1 & & 82.7 & 81.7 & 83.7 & 83.7 & 83.7 & 83.7 & 82.7 & 75.0 & 77.98 & 82.7 & 9 & |BV-D274 \\
\hline 10 & 14.9 & 13.7 & 13.7 & 16.1 & 22.32 & 22.3 & 22.3 & 5.0 & 19.7 & & 86.5 & 87.5 & 87.5 & 87.5 & 87.5 & 85.6 & 76.0 & 81.78 & 84.6 & 10 & $\mid B V-4 / 91$ \\
\hline 11 & 1.9 & 7.1 & 7.1 & 6.0 & 17.31 & 17.3 & 17.3 & 13.7 & 21.0 & 14.9 & & 96.2 & 91.3 & 91.3 & 97.1 & 97.1 & 86.5 & 88.59 & 96.2 & 11 & EG-F728-1-2015-SP1 \\
\hline 12 & 1.9 & 5.0 & 5.0 & 6.0 & 16.11 & 16.1 & 16.1 & 12.6 & 18.5 & 13.7 & 4.0 & & 91.3 & 91.3 & 99.0 & 97.1 & 86.5 & 87.59 & 96.2 & 12 & EG-F728-7-2015-SP1 \\
\hline 13 & 7.1 & 8.1 & 8.1 & 5.0 & 22.32 & 22.3 & 22.3 & 14.9 & 18.5 & 13.7 & 9.2 & 9.2 & & 100.0 & 92.3 & 94.2 & 83.7 & 90.49 & 93.3 & 13 & EG-F862-3-2015-SP1 \\
\hline 14 & 7.1 & 8.1 & 8.1 & 5.0 & 22.32 & 22.3 & 22.3 & 14.9 & 18.5 & 13.7 & 9.2 & 9.2 & 0.0 & & 92.3 & 94.2 & 83.7 & 90.49 & 93.3 & 14 & EG-F862-4-2015-SP1 \\
\hline 15 & 1.0 & 4.0 & 4.0 & 5.0 & 16.11 & 16.1 & 16.1 & 12.6 & 18.5 & 13.7 & 2.9 & 1.0 & 8.1 & 8.1 & & 081 & 87.5 & 88.59 & 97.1 & 15 & EG-F868-2015-SP1 \\
\hline 16 & 1.0 & 6.0 & 6.0 & 2.9 & 18.51 & 18.5 & 18.5 & 14.9 & 19.7 & 16.1 & 2.9 & 2.9 & 6.0 & 6.0 & 1.9 & & 87.5 & 90.49 & 99.0 & 16 & EG-F777-2015-SP1 \\
\hline 17 & 12.6 & 13.7 & 13.7 & 13.7 & 27.62 & 27.6 & 27.6 & 27.6 & $30.4:$ & 29.0 & 14.9 & 14.9 & 18.5 & 18.5 & 13.7 & 13.7 & & 87.58 & 88.5 & 17 & EG-F183-1-2016-SP1 \\
\hline 18 & 11.4 & 10.3 & 10.3 & 8.1 & 23.62 & 23.6 & 23.6 & 19.7 & 26.3 & 21.0 & 12.6 & 13.7 & 10.3 & 10.3 & 12.6 & 10.3 & 13.7 & & 91.3 & 18 & EG-F183-2-2016-SP1 \\
\hline 19 & 1.9 & 5.0 & 5.0 & 2.9 & 18.51 & 18.5 & 18.5 & 16.1 & 19.7 & 17.3 & 4.0 & 4.0 & 7.1 & 7.1 & 2.9 & 1.0 & 12.6 & 9.2 & & 19 & EG-F183-3-2016-SP1 \\
\hline & 1 & 2 & 3 & 4 & 5 & 6 & 7 & 8 & 9 & 10 & 11 & 12 & 13 & 14 & 15 & 16 & 17 & 18 & 19 & & \\
\hline
\end{tabular}

Figure 3: Amino acid identities of Egyptian isolates with other selected infectious bronchitis virus sequence.

In this study, the prevalence of IBV infection in 75 examined farms by rRT-PCR indicated the widespread distribution of the virus all over Egypt. Higher isolation rates were observed in Bani-Sueif $(80 \%)$, Gharbia $(75 \%)$ and Monofia (71\%) Governorates compared to the other localities.

The primary isolation of IBV from positive rRT-PCR samples, via inoculation of 9-11 day- old SPF egg was adopted. After three blind passages of rRT-PCR pooled samples in ECE, marked curling and dwarfing as well as high embryonic mortality were observed. The recorded results were considered suggestive to IBV infection as previously recorded [8].
Identification and genotyping of IBV was performed by the sequencing of hyper variable region (HVR3) of the SP1 gene [9]. Sequence analysis showed that these isolates were subdivided into 2 groups. The first subgroup ( 7 isolates) resembling the variant 1 strains including IBV-IS-1494-06 that match with them $87.5 \%$ to $96.2 \%$ amino acid identity. This finding agreed with previously recorded studies [23]. The second subgroup resembling the new variant 2 strains including isolates IS/885/00 isolated in Israel and Egypt, respectively revealed $(92.3 \%-97.1 \%)$ amino acid identities). This finding agreed with a previously reported study [5]. 


\section{Conclusion}

It could be concluded that different variants of IBV are present in high rate in broiler farms even in vaccinated farms and cause severe economic losses. Therefore, the variant strains vaccine may play a role in spreading IBV in broiler farms. IBV has high mutation rate, consequently, continuous surveillance of new IBV strains is important for understanding the molecular evolution of different genotypes and for selecting candidate virus strains for vaccination regimes.

\section{Conflict of interest}

The authors have no conflict of interest to declare.

\section{References}

[I] International Committee on Taxonomy of Viruses (ICTV): Virus Taxonomy: 2015 Release.http://ictvonline.org/virusTaxonomy.asp? version $=2011 \&$ bhcp $=1$

[2] Butcher, G.D.; Shapiro, D.P. and Miles, R.D. (2011): Infectious Bronchitis Virus: classical and variant strains. One of a series of the Veterinary Medicine-Large Animal Clinical Sciences Department, Florida Cooperative Extension Service, IFAS: VM127.

[3] De Wit, J.J.S.; Cook, J.K.A. and van der Heijden, H.M.J.F. (2010): Infectious bronchitis virus in Asia, Africa, Australia and Latin America-history, current situation and control measures. Rev Bras Cienc Avic, 12: 97-106.

[4] Jackwood, M.W.; Hall, D. and Handel, A. (2012): Molecular evolution and emergence of avian gamma corona viruses. Infect Genet Evol, 12(6):1305-1311.

[5] Abdel-Moneim, A.S.; Afifi, M.A. and ElKady, M.F. (2012): Emergence of a novel genotype of avian infectious bronchitis virus in Egypt. Arch Virol, 157(12):24532457.

[6] Tawfik, H.I.; Salama, E.; Hassan, O.M. and Ahmed, A. (2013): Preparation and evaluation of live bivalent infectious bronchitis vaccine in chicken. Researcher, 5(3):31-35.
[7] Callison, S.A.; Jackwood, M.W. and Hilt, D.A. (2001): Molecular characterization of infectious bronchitis virus isolates foreign to the United States and comparison with United States isolates, Avian Dis, 45(2):492-499.

[8] Office International des Epizooties, OIE (2013): Avian infectious bronchitis. Manual of standards for diagnostic tests and vaccines for terrestrial animals. Paris, 443-455.

[9] Adznar, A.K.; Cough, R.E.; Haydon, D.; Shaw, K.; Britton, P. and Cavanagh, D. (1997): Molecular analysis of the 793/B serotype of infectious bronchitis virus in Great Britain. Avian Pathol, 26(3): 625640.

[10] Altschul, S.F.; Gish, W.; Miller, W.; Myers, E.W. and Lipman, D.J. (1990): Basic local alignment search tool. J Mol Biol, 215(3):403-410.

[11] Tamura, K.; Peterson, D.; Peterson, N.; Stecher, G.; Nei M. and Kumar S. (2011): MEGA5: molecular evolutionary genetics analysis using maximum likelihood, evolutionary distance, and maximum parsimony methods. Mol Biol Evol, 28(10):2731-2739.

[12] El-Mahdy, S.S.; El-Hady, M. and Soliman, Y.A. (2010): Isolation and characterization of nephropathogenic strain of Infectious Bronchitis Virus in Egypt. J Am Sci, 6(9):669-675.

[13] Arbo, S.H.; Ullman, K.; Belák, S. and Baule, C. (2012): Bioinformatics and evolutionary insight on the spike glycoprotein gene of QX- like and Massachusetts strains of infectious bronchitis virus. Virol J, 9(1):211.

[14] Ahmed, A.A.S. (1964): Infekiose Bronchitis des Huhnes in Aegypten. Berl. Munich Tieraztl. Wschr. 77: 481-484.

[15] Eissa, Y.M.; Zaher, A. and Nafai, E. (1963): Studies on respiratory diseases: Isolation of infectious bronchitis virus. $\mathbf{J}$ Arab Vet Med Ass, 23:381-389.

[16] Amin, A. and Mostageer, M. (1977): A preliminary report on an avian infectious bronchitis virus strain associated with 
nephritis-nephrosis Syndrome in chickens. J Egypt Vet Med Ass, 37 (2): 71-79.

[17] Lebdah, M.A.; Eid, A.M.; and El-Shafey, A.M. (2004): Infectious bronchitis virus infection among meat type chickens in Sharkia province (Egypt). Proceeding of the IV. International symposium on avian corona and pneumovirus infections. Rauischholzhausen; Germany; 20-23 June 2004.

[18] Sultan, H.A.; Tantawi, L.; Youseif, A.I. and Ahmed, A.A.S. (2004): Urolithiathis in white commercial egg laying chickens associated with an infectious bronchitis virus. In $6^{\text {th }}$ Sci Conf Egyp Vet Poult Assoc, 155-169.

[19] Hofstad, M.S. (1984): Avian infectious bronchitis. In: Diseases of poultry, $8^{\text {th }}$ ed. Iowa State University Press: Ames, IA, p:429-443.
[20] Bumstead, N.; Huggins, M.B. and Cook, J.K. (1989): Genetic differences in susceptibility to a mixture of avian infectious branchitis virus and Escherichia Coli. Br Poult Sci, 30(1): 39-48.

[21] Cumming, R.B. (1963): Infectious avian nephrosis (uremia) in Australia. Aus Vet J, 39(4):145-147.

[22] Gough, R.E.; Randall, C.J.; Dagless, M.; Alexander, D.J.; Cox, W.J. and Pearson, D. (1992): A new strain of infectious bronchitis virus infecting domestic fowl in Great Britain. Vet Rec, 130(22): 493-494.

[23] Ganapathy, K.; Ball, C. and Forrester, A. (2015): Genotypes of infectious bronchitis viruses circulating in the Middle East between 2009 and 2014. Virus Res, 210:198-204.

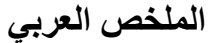

عزل وتصنيف فيروس التهاب الثعب المعدى فى بارى دجاج التسمين من بعض محافظات مصر

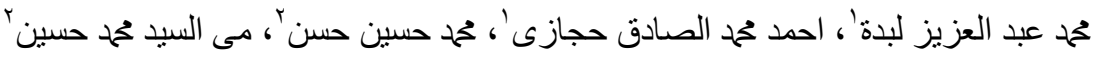

'قسم طب الطيور والار انب ـ كلية الطب البيطرى - جامعة الزقازيق

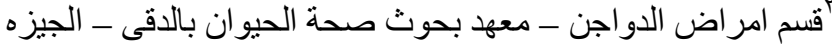

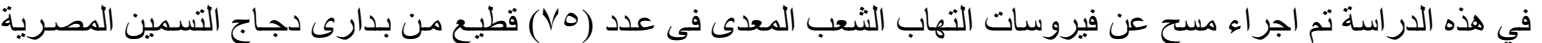



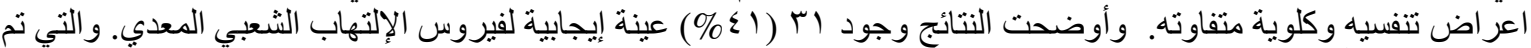

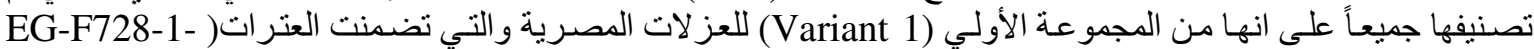
2015-SP1, EG-F728-7-2015-SP1, EG-F862-3-2015-SP1, EG-F862-4-2015-SP1, EG-F888-2015-

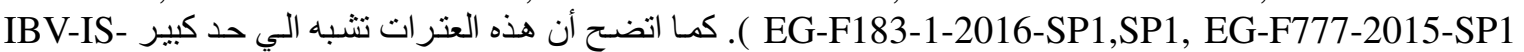

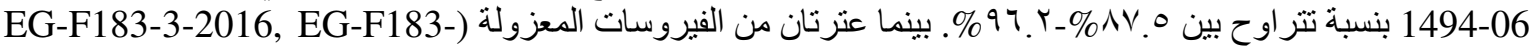

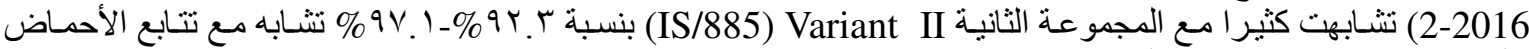

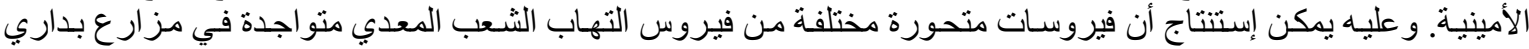
التسمين بنسبة عالية حتى ولو كانت محصنة.
} 